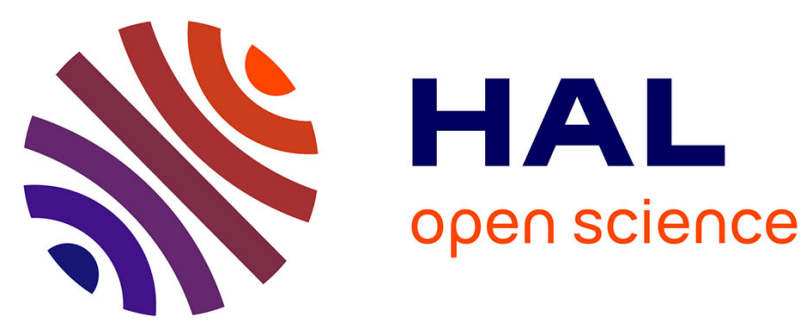

\title{
Challenges for Usability Testing in Ubiquitous Systems
}

Carla Ilane Moreira Bezerra, Rainara Maia Santos, Rossana Maria de Castro Andrade, Ismayle Santos, José Maria Monteiro, Káthia Marçal de Oliveira, Mourad Abed, Houcine Ezzedine

\section{- To cite this version:}

Carla Ilane Moreira Bezerra, Rainara Maia Santos, Rossana Maria de Castro Andrade, Ismayle Santos, José Maria Monteiro, et al.. Challenges for Usability Testing in Ubiquitous Systems. IHM'14, 26e conférence francophone sur l'Interaction Homme-Machine, Oct 2014, Lille, France. ACM, pp.183-188, 2014. hal-01090441

\section{HAL Id: hal-01090441 https://hal.science/hal-01090441}

Submitted on 3 Dec 2014

HAL is a multi-disciplinary open access archive for the deposit and dissemination of scientific research documents, whether they are published or not. The documents may come from teaching and research institutions in France or abroad, or from public or private research centers.
L'archive ouverte pluridisciplinaire HAL, est destinée au dépôt et à la diffusion de documents scientifiques de niveau recherche, publiés ou non, émanant des établissements d'enseignement et de recherche français ou étrangers, des laboratoires publics ou privés. 


\section{Challenges for Usability Testing in Ubiquitous Systems}

\section{Carla Bezerra}

Federal University of Ceará

Fortaleza - CE, Brazil

carlailane@great.ufc.br

\section{Rossana M. C. Andrade}

Federal University of Ceará

Fortaleza - CE, Brazil

rossana@great.ufc.br

\section{Rainara Maia Santos}

Federal University of Ceará

Fortaleza - CE, Brazil

rainarasantos@great.ufc.br

\section{Mourad Abed}

UVHC, LAMIH, CNRS UMR 8201 UVHC, LAMIH, CNRS UMR 8201 mourad.abed@univ-

valenciennes.fr

\section{Káthia Marçal de Oliveira}

UVHC, LAMIH, CNRS UMR 8201

kathia.oliveira@univ-

\section{valenciennes.fr}

\section{José Maria Monteiro}

Federal University of Ceará

Fortaleza - CE, Brazil

monteiro@lia.ufc.br

\section{Ismayle Santos}

Federal University of Ceará

Fortaleza - CE, Brazil

ismaylesantos@great.ufc.br

Houcine Ezzedine

houcine.ezzedine@univ-

valenciennes.fr

(C) ACM, 2014. This is the author's version of the work. It is posted here by permission of ACM for your personal use. Not for redistribution. The definitive version was published in Actes de la $26^{\text {ieme }}$ conférence francophone sur l'Interac-

http://dx.doi.org/10.1145/2670444.2670468

\section{Abstract}

Ubiquitous computing expands both the place where the software system is used and the traditional way of interacting with its users. This happens since

technologies should be fully integrated in the user daily activities in such way they become indistinguishable. So, in this scenario, new characteristics can emerge like calmness, transparency and context awareness that should be evaluated to assure the ubiquitous system quality. One of the methods used for evaluation of traditional systems is usability testing. Then, in this paper, we identify the main challenges to perform usability testing in ubiquitous systems based on an overview of the literature studies and on our own experience in testing this kind of systems. We also describe our ongoing work where we investigate usability testing to be designed considering contextawareness and to be supported by specific

measurements to the ubiquitous computing scenario.

\section{Keywords}

Usability Testing, Ubiquitous Systems, Quality.

\section{Keywords ACM classification}

H.5.m. Information interfaces and presentation (e.g., HCI) : Miscellaneous. H.5.2 User Interfaces. (D.2.2, H.1.2, I.3.6): Evaluation/methodology.

\section{Introduction}

Ubiquitous computing is a new paradigm that makes technological devices that interact with users in the environment invisible to them, shifting their attention 
from the software/hardware to everyday tasks [1] Ubiquitous systems have features of distributed, heterogeneous and user-centered systems. A challenge for these systems is thus to design, implement and test these features as well as to attend issues related to user satisfaction [2].

According to Nielsen [3], usability describes the ease in which users interact with a given interface correctly using system features. Usability testing is an observation method that aims to evaluate interactive systems from the observation of the use of the systems by users [4]. It is then explicitly devoted to analyze in details how users interact with the application for accomplishing well-defined tasks. Typical data collected during user testing are user execution time, number of errors, and user satisfaction. After the test completion, the collected data are then interpreted and used to improve the level of the application usability [5]

Nelly et al. [6] state that the evaluation in ubiquitous systems from the viewpoint of Human-Computer Interaction $(\mathrm{HCI})$ could be difficult, since the evaluation of $\mathrm{HCI}$ approaches tend to be subjective and/or fragmented. From the viewpoint of $\mathrm{HCI}$, one of the best and most used methods for evaluating ubiquitous systems is usability testing (e.g., see $[7,8,9])$.

After a literature review, we have observed the implementation of usability testing in ubiquitous systems is generally performed in the same manner as in traditional systems. However, we have also identified several gaps and challenges of applying usability testing in ubiquitous systems that need more investigation and we gather them to present in this paper based on this review and on our own experience.
Besides that, we present our ongoing research to deal with some of these gaps and challenges.

\section{Literature Review}

We have performed a non-systematic review of the literature to identify different studies in the literature

that proposed evaluation of ubiquitous systems. In this review, 20 papers were analyzed taken into account the following criteria: application domain, measures of usability testing, usability testing approaches in ubiquitous systems, and environment to performing of usability testing (controlled or real).

Regarding the domain of the evaluated ubiquitous applications, they have been diversified. However, most papers performed usability evaluation in Smart Homes $[2,10,11,12,13]$ and Navigating System $[14,15,16$ $17,18]$. Other work performed usability evaluation in other domains $[7,9,19,20,21,22]$ or not really performed any evaluation $[8,23,24,25]$.

In the literature review, several measures were identified to assess the usability of the applications. However, we found out that no paper identifies measures for usability testing that consider the characteristics of ubiquitous applications such as context information. Most of the identified measures are the same used in traditional usability testing systems, for example: List of Tasks Performed [9, 13, $14,15,18,20]$, Learnability $[15,20,22,25]$

Response time $[2,14,16,25]$ and User Satisfaction [7, $11,13,14]$. Only three papers $[8,19,24]$ have identified measures that consider the characteristics of ubiquitous systems. Other papers did not provide measures for usability testing $[7,10,18]$. 
Most papers $[2,7,9,10,12,13,14,15,16,17,20$, $21,22]$ performed usability testing in controlled environments, not in real environments. Moreover, few papers presented specific approaches to usability evaluation for ubiquitous applications and, these approaches that have been identified are not specific to usability tests. In fact, we just found out evaluation frameworks $[8,10]$, usability evaluation processes [11] and measures of usability evaluation in ubiquitous systems $[2,19]$.

\section{Experience Report}

We have been working with $\mathrm{HCI}$ evaluations in ubiquitous systems using software quality measurement. To do that, we have first defined which $\mathrm{HCI}$ quality characteristics of ubiquitous systems should be measured. Using a literature systematic mapping, we have identified the following five characteristics specific for evaluating $\mathrm{HCI}$ in ubiquitous systems:

Context-Awareness (corresponds to the ability to collect contextual information and use them to make adaptations), Transparency (system proactivity, so the user is minimally distracted), Attention (refers to continuous or uninterrupted use of the systems as the user moves through several devices), Mobility (represents an increase of the attention's focus of the user in their everyday activities) and Calmness (prevents humans from feeling overwhelmed by technology). For these characteristics, a set of software measures were defined to evaluate the HCI quality. Examples of such measures are to context-awareness: Adaptation Correctness, Context Correctness and Adaptation Time [26].

The defined measures were collected in evaluations of three ubiquitous applications to mobile devices. The first application is called UbiPrinter, which aims to support the printing of documents by finding the user nearest printer. The second one is called UbiMute that monitor the user calendar looking for events in which the user cannot answer calls, for example: "meeting". Then, this application switched to the "silent" mode of the user's mobile phone. The last application is called GREat Tour, which is a tour guide for the GREat laboratory. It provides information about the environments of the laboratory that the user is visiting.

To execute the measure collection, we use different methods to collect all necessary data to calculate the defined measures: (i) generation of user interaction logs with the application by the code instrumentation; (ii) application of questionnaires to the final user as well as to the application developer; and (iii)

observation form to the evaluator who makes notes while the user is using the application.

We faced some difficulties along the preparation and execution of these tests:

- Each application requires a specific implementation code to collect the necessary data for the

evaluation. For instance, to evaluate Adaptation Correctness, different context information had to be collected for each application: in UbiPrinter, we should automatically collect the Wi-Fi; and in UbiMute, the calendar.

- Each application requires different test procedures. For instance, to observe the behavior of the UbiMute in the real environment, it is required that

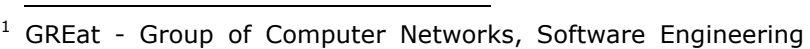
and Systems. 
the application should be used during at least some days in the own users mobile phones. As a consequence, the participation of an observer during the test was not possible. On the other hand, we could assess UbiPrinter and Great Tour with an observer watching users of these applications.

- And, evaluating context-awareness requires the execution of several tests with a detailed planning of all tasks to be followed and the setting of different context information. For instance, to test the context-awareness of Great Tour, three mobile devices were necessary, each one with different level of battery, because this application has a battery level based adaptation.

\section{Challenges}

Based on the literature review about usability testing and in our own experience in $\mathrm{HCI}$ quality evaluation of ubiquitous systems, challenges in performing usability testing of these systems have been identified.

An identified key challenge is related to the environment of usability testing. Most usability testing is performed in the laboratory. However, according to Kim et al. [8], the traditional controlled laboratory tests are not suitable for ubiquitous applications. This is due to the large number of resources demanded to the environment required by ubiquitous systems, which must be the same used in real environment [12]. So, usability testing in ubiquitous systems should be suitable for running in real environments.

Another challenge identified is that ubiquitous environments have more usability factors that should be used, such as contextual variables [10]. A context- aware application has part of its particular behavior dependent of the context [27]; therefore, it is necessary to predict all relevant changes in context and analyze when those changes can impact the behavior of the system application [28]. Usability testing should be mobile, modular and contextual to meet the ubiquitous systems features, and should also employ user-driven tasks to be accurate and relevant [7]. Test cases should be designed considering the context that the user can have in the environments in which the application will run. It is also important to consider the calm interaction related to the user's attention factor. This is a feature that shows the transparency of ubiquitous application in relation to user interaction.

For measures used in usability testing, we found out that most of these measures does not consider the factors of ubiquitous applications. It is a challenge to make the evaluation of the usability of these systems more reliable, and identify measures that consider the ubiquitous features in usability tests [19].

Finally, another challenge is in relation to the implementation of usability testing in ubiquitous systems, because currently they follow the same activities performed in traditional systems. There were not identified in our review one specific approach for usability testing of ubiquitous systems. Thus, research can be conducted to elaborate an approach for usability testing with specific tasks and specific measures to evaluate ubiquitous systems.

\section{Future Work}

Based on the challenges identified in usability testing for evaluating ubiquitous systems, we are working on a research project to try to solve them. The project objective is to define a strategy for planning and 
executing context-aware testing for ubiquitous systems, considering the context, and using measurements.

To that end, we should evolve usability testing to evaluate the complete ubiquitous system. We advocate that the interaction issues in ubiquitous systems go beyond the human-computer relationship,

encompassing the interaction between different devices and systems, which we call in this project actorcomputer interaction, in which the actor can be not only the user, but also, another computer, device or software system in order to better answer the need of invisibility required.

\section{Références}

[1] Maia, M. E., Fonteles, A., Neto, B., Gadelha, R., Viana, W., \& Andrade, R. M. C. LOCCAM-loosely coupled context acquisition middleware. In Proceedings of the 28th Annual ACM Symposium on Applied Computing, pp. 534-541 (2013, March).

[2] Lee, J., \& Yun, M. H. Usability assessment for ubiquitous services: Quantification of the interactivity in inter-personal services. In Management of Innovation and Technology (ICMIT), 2012 IEEE International Conference on (pp. 718-724), (2012, June).

[3] Nielsen, J. Usability Engineering. Boston: Academic Press (1993).

[4] Rubin, J., \& Chisnell, D. Handbook of usability testing: howto plan, design, and conduct effective tests. John Wiley \& Sons.Nielsen, J. Usability Engineering". Boston: Academic Press (2008).

[5] Fiotakis, G., Raptis, D., Avouris, N. Considering Cost in Usability Evaluation of Mobile Applications: Who, Where and When", INTERACT '09 Proceedings of the 12th IFIP TC 13 International Conference on Human-Computer Interaction: Part I (2009).
Based on this project, we intend to build a specific approach to usability testing for ubiquitous systems. To reach this objective, this project includes: (i) Establish a software process for context-awareness testing based on evidence; (ii) Define measures to evaluate the interoperability of ubiquitous systems; (iii) Design context-awareness test cases based on measurements; and (iv) Develop and experimentally evaluate support tools for collecting measures.

\section{ACKNOWLEDGMENTS}

This work is a partial result of the Maximum project supported by FUNCAP (FAPs/INRIA/INS2iCNRS 11/2011) and Cactus project supported by CNPQ (Universal 14/2013).

[6] Neely, S.; Stevenson, G.; Kray, C.; Mulder, I.; Connelly, K. and siek, K.A. Evaluating pervasive and ubiquitous systems," IEEE Pervasive Computing, Vol. 7, no. 3 pp. 85-8 (2008)

[7] Riihiaho, S. User testing when test tasks are not appropriate. In European Conference on Cognitive Ergonomics: Designing beyond the Product Understanding Activity and User Experience in Ubiquitous Environments (p. 21), (2009, September). [8] Kim, H. J., Choi, J. K., \& Ji, Y. Usability evaluation framework for ubiquitous computing device. In Convergence and Hybrid Information Technolog. ICCIT'08,(Vol. 1, pp. 164-170), (2008, November). [9] Silveira, C., Eloy, L., \& Monteiro, J. M. A query language for data access in ubiquitous environments. Proceedings CILEI electronic journal, (2010).

[10] Kim, S. H., Kim, S. W., \& Park, H. M. Usability challenges in ubicomp environment. Proc. of Int'l. Ergonomics Assoc. (2003).

[11] Lee, J., Song, J., Kim, H., Choi, J., \& Yun, M. H. A user-centered approach for ubiquitous service 
evaluation: an evaluation metrics focused on humansystem interaction capability. In Computer-Human Interaction (pp. 21-29), (2008, January).

[12] Acampora, G., Loia, V., \& Vitiello, A. Using ANFIS and $\mathrm{FML}$ for deploying transparent services in smart environments. In Innovative Mobile and Internet Services in Ubiquitous Computing (IMIS), Sixth International Conference on (pp. 628-633), (2012). [13] Song, I. J., \& Cho, S. B. Bayesian and behavior networks for context-adaptive user interface in ubiquitous home environment. Expert Systems with Applications, 40(5), 1827-1838, (2013).

[14] Ross, T., \& Burnett, G. Evaluating the humanmachine interface to vehicle navigation systems as an example of ubiquitous computing. International Journa of Human-Computer Studies, 55(4), 661-674 (2001).

[15] Poláček, O., Grill, T., \& Tscheligi, M. Towards a navigation system for blind people: a wizard of oz study. ACM SIGACCESS Accessibility and Computing, (104), 12-29, (2012).

[16] Noguera, J. M., Segura, R. J., Ogáyar, C. J., \& Joan-Arinyo, R. A scalable architecture for 3D map navigation on mobile devices. Personal and ubiquitous computing, 17(7), 1487-1502, (2013).

[17] Maly, I., Mikovec, Z., Vystrcil, J., Franc, J., \& Slavik, P. An evaluation tool for research of user behavior in a realistic mobile environment. Personal and ubiquitous computing, 17(1), 3-14, (2013).

[18] Rodriguez-Sanchez, M. C., Moreno-Alvarez, M. A., Martin, E., Borromeo, S., \& Hernandez-Tamames, J. A Accessible smartphones for blind users: A case study for a wayfinding system. Expert Systems with

Applications. Journal Expert Systems with Applications, (2014).

[19] Scholtz, J., \& Consolvo, S. Toward a framework for evaluating ubiquitous computing applications. Pervasive Computing, IEEE, 3(2), 82-88 (2004).
[20] McGlinn, K., O'Neill, E., Gibney, A., O'Sullivan, D. \& Lewis, D. SimCon: A Tool to Support Rapid Evaluation of Smart Building Application Design using Context Simulation and Virtual Reality. J. UCS, (2010).

[21] Gavalas, D., \& Kenteris, M. A web-based pervasive recommendation system for mobile tourist guides. Personal and Ubiquitous Computing , (2011).

[22] Gavalas, D., \& Kenteris, M. Evaluation of a web recommender system in electronic and mobile tourism. International Journal of Web Engineering and

Technology, 7(1), 4-21, (2012).

[23] Ranganathan, A., Al-Muhtadi, J., Biehl, J., Ziebart, B., Campbell, R. H., \& Bailey, B. Towards a pervasive computing benchmark. In Pervasive Computing and Communications Workshops. PerCom 2005 Workshops, (pp. 194-198), (2005, March).

[24] Rubio, J. M. L., \& Bozo, J. P. Approach to a Quality Process for the Ubiquitous Software Development. In Electronics, Robotics and Automotive Mechanics

Conference, (pp. 701-705), (2007).

[25] Tang, L., Yu, Z., Zhou, X., Wang, H., \& Becker, C. Supporting rapid design and evaluation of pervasive applications: challenges and solutions. Personal and ubiquitous computing, 253-269, (2011).

[26] Santos, R. M., de Oliveira, K. M., Andrade, R. M., Santos, I. S., \& Lima, E. R. A Quality Model for HumanComputer Interaction Evaluation in Ubiquitous Systems. In Human Computer Interaction (pp. 63-70). Springer International Publishing (2013).

[27] Tse, T. H.; Yau, S. S.; Chan, W. K.; Lu, H.; Chen, T. Y. Testing Context-Sensitive MiddlewareBased Software Applications. In 28th Annual International Computer Software and Applications Conference, Washington, p. 458-466 (2004).

[28] Wang, Z.; Elbaum, S.; Rosenblum, D. S. (2007). Automated Generation of Context-Aware Tests. In Proceedings of the 29th international conference on Software Engineering (ICSE '07), p. 406-41. 